\title{
REFLEXIVE ABILITIES TO SELF-REGULATION AS A COGNITIVE COMPONENT OF PERSONALITY'S PSYCHOLOGICAL WELL-BEING
}

https://doi.org/10.37096/SHDISJ-20-1.1-0006

\author{
Prokopovych Yevhenii \\ ORCID: 0000-0002-8601-5419 \\ Shykovets Serhii \\ ORCID 0000-0003-1299-6434
}

\begin{abstract}
The article is devoted to the theoretical and methodological investigation of the problem of the features of the reflexive abilities to self-regulation and the skills of students, which they use in the process of solving the problem, at the cognitive level of functioning of the reflective experience. Together with the theoretical analysis of scientific work related to the study of this topic, in the article we tried to operationalize them, that is, to select indicators that reflect the quantitative aspects of their formation, and to empirically determine the levels of students' ability to self-regulate and cognitively.

To determine the significance for students of the development of reflexive abilities to self-regulation, we used the scale "Tasks for the development of self-regulation abilities" from the methodology "Life tasks for self-development", developed by O. Savchenko and Y. Domanova, with which help determine the level of actualization of students' tasks through the regulation at the current time on the appropriate scales.

Using the method of O. Savchenko "Reflexive skills (cognitive level)" the generalized indicators of the average values of reflexive skills of the cognitive level were defined on such scales as "Ability to explain to yourself and others the course of their reasoning" emotional experiences, control their course, maintain a sense of confidence", "Keep yourself in the scope of reflections and analyze the reasons for their own actions, causes of failures", "Ability to organize the work the search for a solution, test their assumptions", "Ability to evaluate results by different criteria", "Ability to be aware of various aspects of the course of decision-making processes: cognitive, emotional, behavioral" and the overall level of development of reflexive ego skills. From the obtained data we can conclude that the students on average have the lowest assessment of their reflexive cognitive skills on the scale "Ability to evaluate results by different criteria, formulate evaluative judgments". The overall level of students' reflexive cognitive skills is medium.
\end{abstract} being.

Keywords: reflexive skills, educational activity, personality's psychological well-

Introduction.

In the light of the development of higher education of Ukraine towards the achievement of European standards of schooling and the attitude towards the student as a subject of educational activity, the development of their personal selfregulation at various levels should help to increase their level of psychological readiness for 
"SOCIALIZATION \& HUMAN DEVELOPMENT" INTERNATIONAL JOURNAL

educational and professional life, provided the timely definition and development of psychological qualities of the individual, which contribute to the development of personal self-regulation. Reflectivity as a process and reflection as a factor in the success of such an activity play an important role in this process. Therefore, it becomes necessary to investigate the connection between personal and cognitive qualities that, in combination with regulatory and reflexive capacity, ensure the success of students' learning process. Starting from the 80 s of the last century, great interest in psychological and pedagogical works has caused the study of problems of students' self-regulation, components, mechanisms, principles, factors of self-regulated learning, etc. Particularly relevant is the study of psychological features of components of self-regulated learning, namely: conscious setting of learning goals and objectives, the use of strategies and mechanisms for their implementation, analysis of learning and its effectiveness at different levels, conscious correction, use of reflective learning abilities, etc. The most effective study of the characteristics of reflexive abilities to self-regulation and students' skills is possible through the use of a complex of psychodiagnostic tools aimed at studying such variables, which, on the one hand, will act as determinants of personal selfregulation, and on the other - features that determine the levels of developmental levels of developmental levels. to selfregulation and students' skills as subjects of cognitive learning.

\section{Theoretical background}

Cognitive activity of students in selfregulated learning is considered in the world of psychological science as a factor of effectiveness of educational activity.
Cognitive abilities to self-regulated learning, its corresponding motivation develops in the process of educational activities (Zimmerman, 2011). Underdevelopment cognitive processes in intellectual and educational student activity does not allow them to effectively manage their own mental processes, and therefore, reduces the effectiveness of learning (Schunk \& Greene, 2018).

Studies of reflection and its connection with cognitive and metacognitive aspects of educational activity occupy an important place in the modern world of psychological science, because it is the reflexive abilities that is a kind of metacognitive mechanism that regulates students' educational and intellectual activity and directly influences personality. (Andrade \& Brown, 2016). Acquiring knowledge to improve learning requires sufficient cognitive development of students' self-regulated learning (Zimmerman \& Kitsantas, 2006). Students need to be regulated to overcome the learning difficulties their metacognitive processes. Actually, conscious use of their cognitive strategies makes students more autonomous and self-determined in overcoming difficulties (Cleary \& Kitsantas, 2017).

Among modern domestic scientists who have studied the problem of reflexivity, reflexive skills and of cognitive aspects of students' self-regulated learning, the works of I. Pasichnik and S. Maksimenko (cognitive-style features of personality) should be distinguished in educational activity) (Pasichnyk and Maksimenko, 2010), O. Savchenko (Reflexive Competence in Learning) (Savchenko, 2016), A. Ravchyna (Cognitive Strategies and Reflection in Learning) (Ravchina, 2015), 
"SOCIALIZATION \& HUMAN DEVELOPMENT" INTERNATIONAL JOURNAL

T. Khomulenko and T. Dotsevych (Metacognitive Processes of Personality, meta-memory in training) (Khomulenko and Dotsevich, 2014), V. Kalamazh (reflexivity and metacognition in students' project activity), O. Penkova (value aspects of self-regulation) (Penkova, 2016), M. Teslenko and N. Yudina (self-regulation of educational activity) (Teslenko and Yudina, 2018) and others.

The analysis of scientific works has allowed us to state that cognitive processes and reflexivity are important regulatory mechanisms of students' educational activity at the individual-personal and cognitive levels respectively. The results of the theoretical analysis indicated the need to study students 'reflective skills at the cognitive level, and this allowed us to develop a methodological scheme for further empirical study of the features of students' reflective ability to self-regulate and skills (Balashov, 2019).

\section{Purpose and methodology}

The purpose of our study is theoretical analysis and empirical study of levels of students' self-regulation ability and cognitive skills. The achievement of this goal led to the following tasks: to analyze and summarize existing approaches to the problems of studying self-regulation abilities and students 'skills at cognitive level and to empirically investigate the features of levels of self-regulation abilities and students' skills at cognitive level.

Research methods: theoretical and methodological analysis of categoricalconceptual field of problems; critical analysis and comparison of major aspects of students' reflective abilities to selfregulate and reflective skills at cognitive level; theoretical synthesis of components of students' reflective abilities to selfregulation and reflexive skills at cognitive level; empirical detection with the help of a certain diagnostic toolkit of reflexive abilities for self-regulation and reflexive skills of students at cognitive level.

An empirical study was conducted at the faculty of psychology at Taras Shevchenko National University of Kyiv. In order to determine the levels of selfregulation ability and students' skills at the cognitive level, a sample of 35 students in the age range of 17 to 21 years was formed ( $\mathrm{M}$ age $=20.83, \mathrm{SD}=1.73$ ). To determine the importance for students of developing reflexive self-regulation abilities we used the Capability Task Scale to self-regulation "from the methodology" Life tasks for selfdevelopment "developed by O. Savchenko and Y. Domanova. The group of life tasks identified in this scale is specified in statements that reflect life's tasks for the development of abilities to manage various forms of one's own activity, restore their resources and control psychological states (Savchenko, 2016: 167).

The subjects evaluated the statements on a 4-point scale for the degree of relevance: 0 points - absolutely not relevant; 1 point - practically not actual; 2 points - relevant to some extent; 3 points very relevant. We used the following indicators: the total indicator of the significance of the tasks for the development of self-regulation abilities in the present (calculated as the sum of the estimates obtained on the scale of assessment of current tasks in the current time);

the total indicator of the significance of the tasks for the development of selfregulatory abilities in the near future (calculated as the sum of the estimates obtained on the scale of assessment of life tasks for the short term); 
"SOCIALIZATION \& HUMAN DEVELOPMENT" INTERNATIONAL JOURNAL

average indicators of the importance of the tasks for the development of the ability to self-regulation in the present;

the average of the significance of the tasks to develop the ability to selfregulation in the short term.

\section{Results}

The results obtained show that according to the Self-Regulation Task Scale, $41.30 \%$ of participants had a low level of actualization of current selfregulatory tasks, $54.35 \%$ had an average level, and only $4.35 \%$ had a high level. The results are presented at the Figure 1.

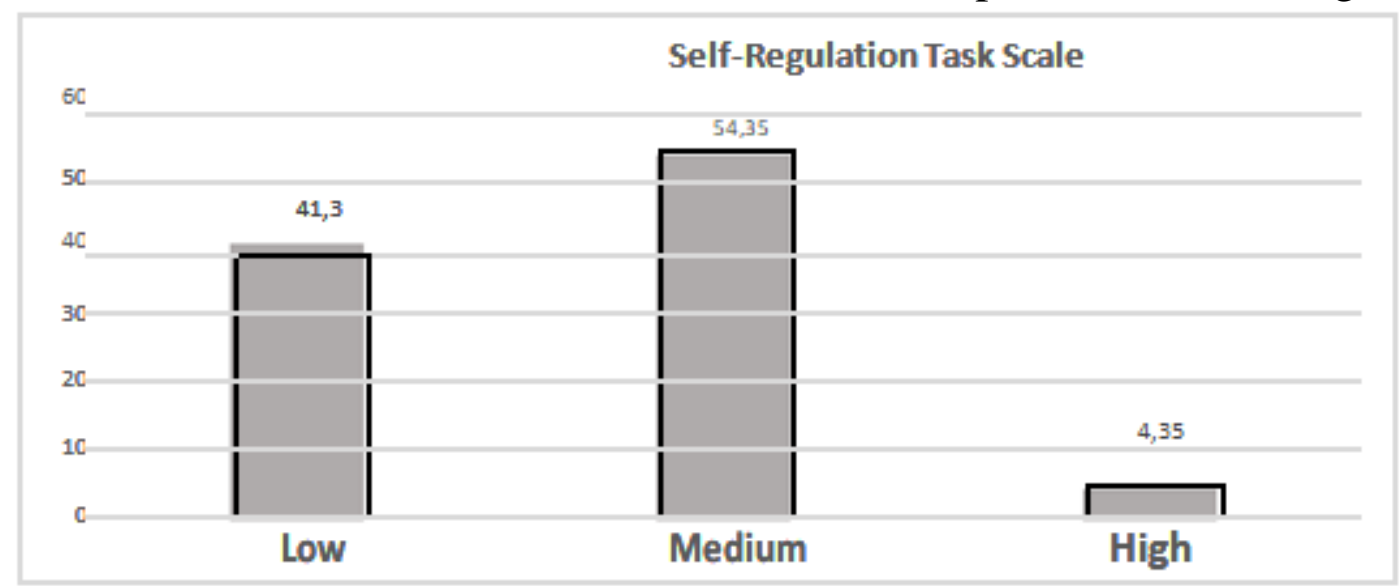

Fig. 1. Indicators of the level of actualization of tasks for self-regulation in the present time, $\%$.

For a group of subjects with a generally high level of actualization on the scale of "self-regulation", the assessment of most of the reflexive abilities included in the structure of this scale is currently at a high level. This means that such students are aware of the dependence of future casework on the level of skill development to quickly mobilize resources, rebuild them in the short term, spend economically in problem-solving situations and in complex activities. Analyzing one's mental states while taking action today, rethinking the means used to solve problems, and probable events is an important reason for setting the task of developing behavioral self-regulation skills in the near future (Savchenko, 2016: 186).

According to O. Savchenko, "the researchers who get high scores on this factor tend to stimulate their own activity, to adequately assess the situation and their ability to control its course. Such persons consciously approach their own criteria for evaluating the success of their activity, they try to develop their ability to be aware of and control emotions and actions, to rationally treat their own resources, to economically spend them in stressful situations, and to quickly recover for further activity"(Savchenko, 2016). 167).

For the group of subjects with a generally low level of actualization on the "self-regulation" scale, the evaluation of all the reflexive abilities within the structure of this scale is quite low at present. Thus, it can be concluded that those with low levels of self-regulation ability are not currently willing to spend the time and effort to develop their own control and regulation skills, as they do not feel consciously aware of the subject control events. Passive attitude to the problem solving process and low level of awareness to their actions and strategies: factors that prevent them from feeling their ability to control their emotions and actions, to form a view of themselves as an object that can be 
"SOCIALIZATION \& HUMAN DEVELOPMENT" INTERNATIONAL JOURNAL

consciously managed (Savchenko, 2016: 186).

Table 1 presents in more detail the data obtained on the Scale for the Development of Self-Regulation. The data in Table 1 indicate that the level of $+6,2$ ).

Table 1. Data on the scale "Tasks for the development of self-regulation" (methodology "Life tasks for self-development" O. Savchenko, Ya. Domanova)

\begin{tabular}{|l|l|l|l|}
\hline № & Life's tasks & $\begin{array}{l}\text { Average in } \\
\text { the present }\end{array}$ & $\begin{array}{l}\text { Average in } \\
\text { the closest } \\
\text { future }\end{array}$ \\
\hline 1 & $\begin{array}{l}\text { Learn the techniques of stimulating your activity } \\
\text { (self-praise, self-support, self-punishment, etc.) }\end{array}$ & 1.70 & 1.65 \\
\hline 7 & $\begin{array}{l}\text { Learn how to quickly assess the situation, your condition, } \\
\text { to carry them for the purpose of activity }\end{array}$ & 1.96 & 1,57 \\
\hline 10 & $\begin{array}{l}\text { Establish your own criteria and standards that will } \\
\text { adequately assess the success of your business }\end{array}$ & 1,78 & 1,57 \\
\hline 15 & $\begin{array}{l}\text { Develop the ability to be aware of your emotions, use them } \\
\text { as clues in difficult situations }\end{array}$ & 2,11 & 1,76 \\
\hline 19 & $\begin{array}{l}\text { To develop the ability to rationally control their resources, } \\
\text { to spend them economically in a state of stress, high stress }\end{array}$ & 2 & 1,76 \\
\hline 22 & $\begin{array}{l}\text { Identify ways and techniques to quickly recover your } \\
\text { strengths and resources }\end{array}$ & 2,09 & 1,46 \\
\hline 26 & $\begin{array}{l}\text { Learn to control your emotions, actions, adjust the pace and } \\
\text { timing of things without delaying them until the last moment }\end{array}$ & 2,02 & 1,63 \\
\hline & The average value & 13,66 & 11,42 \\
\hline & The average total value on a scale & \\
\hline
\end{tabular}

Among the reflective abilities of both present and future, the most important is the ability to "understand their emotions, use them as clues in difficult situations" (2.11 points - present; 1.76 - future), the ability to "identify ways and techniques of the fast restoration of their forces and resources "(2.09 points - present; 1.76 future), developed the ability to" rationally control their resources, economically spend them in a state of stress, increased load "(2 points - present; 1.65 - future). At the same time, on average, there is a sharp decrease in the relevance of the ability to "control their emotions, actions, adjust the pace and timing of cases without delaying them until the last moment" (2.02 points - present time; 1.46 - the future). High importance of significance of self-regulatory tasks localized at the current time interval $(\mathrm{M}=$ $13.66+5.1)$ outweighs the level of significance of self-regulatory tasks localized in the near future $(\mathrm{M}=11.41$ 
"SOCIALIZATION \& HUMAN DEVELOPMENT" INTERNATIONAL JOURNAL

surveyed, the task to learn how to quickly assess the situation, their condition, to correlate them with the purpose of activity is relevant to varying degrees $(56.5 \%$ relevant to the average, for $19.6 \%$ - very relevant), for $23,9 \%$ is practically irrelevant. The task is to formulate own criteria and standards that will adequately evaluate the success of their activities for
$69.5 \%$ of the respondents relevant to different extent (for $47.8 \%$ relevant on average, for $21.7 \%$ - very relevant), for $17.4 \%$ - practically irrelevant, and only for $13.1 \%$ - absolutely out of date. (self-praise, self-support, self-punishment, etc.)

In general, the results are presented in Table 2.

Table 2. Percentage distribution of data on the scale "Tasks for the development of selfregulation" in the present time (the methodology "Life tasks for self-development"

O. Savchenko, J. Domanova).

\begin{tabular}{|l|l|l|l|l|l|}
\hline № & $\begin{array}{l}\text { Life's tasks } \\
\text { not relevant } \\
\text { \% }\end{array}$ & $\begin{array}{l}\text { Practically } \\
\text { not relevant } \\
\text { \% }\end{array}$ & $\begin{array}{l}\text { Relevant to } \\
\text { some extent } \\
\text { \% }\end{array}$ & $\begin{array}{l}\text { Very } \\
\text { relevant } \\
\text { \% }\end{array}$ \\
\hline 1 & $\begin{array}{l}\text { Learn the techniques of } \\
\text { stimulating your activity } \\
\text { (self-praise, self-support, self- } \\
\text { punishment, etc.) }\end{array}$ & 10,9 & 26,1 & 45,7 & 17,4 \\
\hline 7 & $\begin{array}{l}\text { Learn how to quickly assess the } \\
\text { situation, your condition, } \\
\text { to carry them for the purpose of } \\
\text { activity }\end{array}$ & 0 & 23,9 & 56,5 & 19,6 \\
\hline 10 & $\begin{array}{l}\text { Establish your own criteria and } \\
\text { standards that will adequately } \\
\text { assess the success of your business }\end{array}$ & 13 & 17,4 & 47,8 & 21,7 \\
\hline 15 & $\begin{array}{l}\text { Develop the ability to be aware of } \\
\text { your emotions, use them as clues } \\
\text { in difficult situations }\end{array}$ & 2,2 & 13 & 56,5 & 28,3 \\
\hline 19 & $\begin{array}{l}\text { To develop the ability to rationally } \\
\text { control their resources, to spend } \\
\text { them economically in a state of } \\
\text { stress, high stress }\end{array}$ & 4,3 & 23,9 & 39,1 & 28,3 \\
\hline 22 & $\begin{array}{l}\text { Identify ways and techniques to } \\
\text { quickly recover your strengths and } \\
\text { resources }\end{array}$ & 4,3 & 19,6 & 39,1 & 37 \\
\hline 26 & $\begin{array}{l}\text { Learn to control your emotions, } \\
\text { actions, adjust the pace and timing } \\
\text { of things without delaying them } \\
\text { until the last moment } \\
\text { The average value }\end{array}$ & 6,5 & 19,6 & 5,2 & \\
\hline
\end{tabular}

Using them we can conclude that the task is relevant for the largest proportion of respondents "To develop the ability to be aware of their emotions, to use them as clues in difficult situations" (56.5\% - actual on average, $28.3 \%$ - very actual) and "Learn to control their emotions, actions, regulate the pace and timing of cases, not tightening them to the last moment " $(52.2 \%$ - topical on average, $28.3 \%$ - very topical). 
Also significant is the proportion of persons for whom the task is "Learn to quickly assess the situation, their condition, relate them to the purpose of activity" $(56.5 \%$ - very average, $19.6 \%$ - very relevant). According to O. Savchenko, "high responsibility, a tendency to accumulate internal tension, not the formation of mechanisms of involuntary control of their emotions and actions during the defeat - factors which awareness causes the increased level of significance for the subject of tasks for the development of abilities to self-regulation" ( Savchenko, 2016: 168). The high importance of life tasks for the development of self-regulation in the current period of life is associated with high activity of the subject, his willingness to solve problems and overcome difficulties through the use of rational techniques and volitional efforts (Savchenko, 2016: 168). Thus, in the study group of students, the vital task of developing self-regulation skills becomes relevant, since students are first of all aware of the need to develop and practice their skills, to use them as clues in difficult situations, control their emotions, actions, adjust the pace and timing of cases without delaying them until the last moment, quickly assess the situation, their condition, relate them to the purpose of the activity, as well as determine ways and methods of rapid recovery of their strength and resources.

Diagnostic results of the study group by the method "Reflexive skills (cognitive level)" O. Savchenko made it possible to conclude that in the study group is dominated by the average level of overall development of reflexive cognitive skills.

Below we present an analysis of the results on separate scales of the methodology. The scale "Ability to explain to yourself and others the course of your thinking, the reasons for choosing a certain way to decide strategies" in its structure integrates techniques for the effective application of the elect means of solving the problem, namely: to be aware of the selected intellectual means used to solve the reflexive task; flexible transition from the reflective plane to the plane of action, using the chosen tool in practice; describe the results of their own reflexive acts, reflective experiences; explain the appropriateness of the selected remedy; quickly evaluate options for the solution internally (Savchenko, 2016: 65-66). The higher the level of development of skills to understand and explain to themselves the reasons for choosing a certain solution, strategies, the more formed is the individual style of volitional selfregulation, which is primarily manifested in the ability to modeling of forms of own activity taking into account internal and external conditions and a high level of flexibility. It was found that in the study group, the average level of development of reflexive skills prevails to explain to themselves and others the course of their reasoning, the reasons for choosing a certain solution, strategies.

The scale "The ability to be aware of your own emotional experience, control their course, support feeling of confidence "describes the techniques that are responsible for the awareness and analysis of emotional experiences, for controlling their course. Increasing the level of development of this skill prevents situations that lead to the development of depressive states. The core of this skill is formed not by self-regulation skills, but by cognitive processes of awareness, comparison, isolation of essential features and behavioral attitudes to quickly switch 
"SOCIALIZATION \& HUMAN DEVELOPMENT" INTERNATIONAL JOURNAL

attention, to ignore complications and failures due to easy, irresponsible attitude to certain aspects of one's life (Savchenko, 2016): 68 .

It was found that in the study group, the average level of development of reflexive skills is to be aware of their own emotional experiences, to control their course, to maintain a sense of confidence. From the presented data we can conclude that the biggest problems on this scale students feel with the ability to navigate intuitive guesses in the form of emotional feelings $(\mathrm{Xm}=2.77$ points $)$, to consider many factors and circumstances when evaluating their success $(\mathrm{Xm}=3.16$ points), to make metacognitive judgments ("when I get acquainted with the conditions of the task, I have a feeling of confidence (or uncertainty) that I can" - Xm $=3.19$ points).

The scale "Ability to keep yourself in the plane reflective reflections, analyze the reasons for one's own actions, causes of failures »describes the ability to keep oneself in the plane of reflection. The core of this group of skills were techniques aimed at selecting the most appropriate means of solving the problem. Researchers with a high level of development of these skills feel active subjects of their own life, they understand that they can control their own behavior, control strong emotional manifestations that may prevent them from realizing their intentions and goals. They easily solve the problems of meaningmaking, giving meaning to their own actions and desires, which allows them to experience inner freedom, to enjoy the pleasure of manifestations of their own activity. Reflective skill developed enhances the personal capacity of the subject it does his more confident in his own ability to overcome difficult life situations, solve difficult tasks (Savchenko, 2016: 68). It is established that in the studied the group is dominated by the average level of development of reflexive skills to keep themselves in the plane of reflective reflections, to analyze the reasons for their own actions, the causes of failures. From the presented data we can conclude that the biggest problems on this scale students feel with the ability to slow down impulsive decisions, additionally weigh and think, even if there is an idea about the solution of the problem $(\mathrm{Xm}=$ 3.48 points), the ability to analyze the causes of error during failure $(\mathrm{Xm}=3.52$ points), ability to understand the source and cause of a new assumption while solving the problem $(\mathrm{Xm}=3.52$ points $)$.

\section{Discussion}

The process of conducting our research was divided into theoretical and methodological analysis of categoricalconceptual field of problems; critical analysis and comparison of major aspects of students' reflective abilities to selfregulate and reflective skills at cognitive level; theoretical synthesis of components of students' reflective abilities to selfregulation and reflexive skills at cognitive level; empirical detection with the help of a certain diagnostic toolkit of reflexive abilities for self-regulation and reflexive skills of students at cognitive level.

In this approach, in our opinion, the uniqueness of this study is quite high in comparison with the researches already existing (Andrade, \& Brown, 2016; Ravchyna, 2015; Teslenko, \& Yudina, 2018).

The study was conducted in several stages. At the organizational stage, theoretical information concerning the issue of cultural styles and well-being factors for different ethnic groups was 
"SOCIALIZATION \& HUMAN DEVELOPMENT" INTERNATIONAL JOURNAL

elaborated. In the second stage, empirical research was conducted using standardized techniques. The next stage was the processing and interpretation of the results.

In addition, there are limitations to the results obtained. Thus, the study hypothesis was tested only on young representatives of the country population from the students' environment. However, it is also promising to study the situation in the society in general. This study opens up the potential for further scientific research and highlights the relevance of the chosen direction of scientific research.

\section{Conclusion}

To determine the importance for students of the development of reflexive abilities to self-regulation, we used the scale "Tasks for the development of selfregulation abilities" from the methodology "Life tasks for self-development", developed by O. Savchenko and Ya. Domanova, by which we determined the indicators of the level of actualization of students' tasks regulation. currently on the appropriate scales. In general, the results suggest that the task of "Developing the ability to be aware of their emotions, using them as clues in difficult situations", "Learning to control their emotions, actions, adjusting the pace and timing of cases without delaying them, is quite relevant for the largest number of respondents. until the last moment "and" Learn to quickly assess the situation, your condition, relate them to the purpose of the activity ". Using the method of O. Savchenko "Reflexive skills (cognitive level)" (Table 3) we defined generalized indicators of the average values of reflexive skills of the cognitive level on such scales as "Ability to explain to yourself and others the course of their reasoning, reasons for choosing a certain solution, strategies emotional experiences, controlling their course, maintaining a sense of confidence ", "Maintaining yourself in the plane of reflective reflections, analyzing the reasons for your own actions, causes of failures", "Ability to organize your work with seeking a solution to verify their assumptions", "Ability to carry out the evaluation of the results according to various criteria, formulate valuejudgments", "The ability to understand various aspects of processes to find solutions, cognitive, emotional, behavioral, and the general level of cognitive abilities reflective level". From the obtained data we can conclude that students have the lowest scores on their reflexive cognitive skills on the scale "Ability to evaluate results by different criteria, formulate judgmental judgments". The overall level of reflexive development of students' cognitive level is average.

Table 3. Data on the scale "Tasks for the development of self-regulation" (methodology "Life tasks for self-development" O. Savchenko, Ya. Domanova)

\begin{tabular}{|l|l|l|l|}
\hline № & Scale & $\begin{array}{l}\text { Average } \\
\text { point }\end{array}$ & Level \\
\hline 1 & $\begin{array}{l}\text { Ability to explain to yourself and others the course of your } \\
\text { reasoning, the reasons for choosing a certain } \\
\text { solutions, strategies }\end{array}$ & 23,32 & Medium \\
\hline 2 & $\begin{array}{l}\text { Ability to be aware of one's own emotional experiences, to } \\
\text { control their course, to maintain a sense of confidence }\end{array}$ & 24,44 & Medium \\
\hline 3 & $\begin{array}{l}\text { Keep yourself in the plane of reflective thinking, analyze the } \\
\text { reasons for your own actions, the causes of failures }\end{array}$ & 26,22 & Medium \\
\hline
\end{tabular}


"SOCIALIZATION \& HUMAN DEVELOPMENT" INTERNATIONAL JOURNAL

\begin{tabular}{|l|l|l|l|}
\hline 4 & $\begin{array}{l}\text { Ability to streamline the process of finding a solution, to } \\
\text { verify their assumptions }\end{array}$ & 18,7 & Medium \\
\hline 5 & $\begin{array}{l}\text { Ability to evaluate results by different criteria, formulate } \\
\text { judgment judgments }\end{array}$ & 21,1 & Medium \\
\hline 6 & $\begin{array}{l}\text { Ability to be aware of various aspects of the decision- } \\
\text { making process: cognitive, emotional, behavioral }\end{array}$ & 21,88 & Medium \\
\hline 7 & $\begin{array}{l}\text { The general level of development of reflexive cognitive } \\
\text { skills }\end{array}$ & 135,66 & Medium \\
\hline
\end{tabular}

The prospect of further research is seen in the detailed study of the development of components of psychological self-regulation of students' educational activity in the process of metacognitive monitoring, as well as the students' reflective skills as regulatory mechanisms of students' educational activity at the personal level.

\section{Conflict of interests}

There is no real conflict of interests at the time of writing this article or potential conflicts of interest for authors with responsible persons or any other person third parties on the subject matter of the article and related areas of legal research.

Acknowledgments. The study did not receive a grant from any financial agency in state, commercials or the nonprofit sector.

\section{References}

Andrade, H. \& Brown, G. (2016). Student Self-Assessment in the Class-room, in Gavin T. L. Brown, Lois R. Harris (Eds.), Handbook of Human and Social Conditions in Assessment (p. 319-334). New York: Routledge.

Balashov, E., Pasichnyk, I., Kalamazh, R., Dovhaliuk, T. \& Cicognani, E. (2018). Psychological, Emotional and Social Wellbeing and Volunteering: A Study on Italian and Ukrainian University Students. Youth Voice Journal,18, 1-22.
Cleary, T. J. \& Kitsantas, A. (2017). Motivation and Self-Regulated Learning Influences on Middle School Mathematics Achievement. School Psychology Review, Vol. 46, No. 1, 88-107.

Khomulenko, T. B. \& Dotsevych T. I. (2014). Metapamiat: naukovi pidkhody ta eksperymentalnointrospektyvna metodyka doslidzhennia [Metamemory: Scientific Approaches and Experimental-Introspective Methodology of Research]. Bulletin of $\mathrm{H}$. Skovoroda Kharkiv National Pedagogical University. Series "Psychology", \#49, 193-211 [in Ukrainian].

Pasichnyk, I. D. \& Maksymenko S. D. (2010). Role of Cognitive and Style Peculiarities of Personality in the Process of Learning Activity [Rol kohnityvnyn-styliovykh

osoblyvostej osobystosti v protsesi navchalnoji dijalnosti]. Scientific Notes of National University of Ostroh Academy. Series "Psychology and Peda-gogy", 14, 3 10 [in Ukrainian].

Penkova, O. I. (2016). Problem of SelfRegulation of Personality: Value Aspect [Problema samorehuliatsiji osobystosti: tsinnisnyj aspekt]. Scientific Bulletin of Kherson State University. Series "Psychological 
Sciences", 2(1), 114-118 [in Ukrainian].

Ravchyna, T. I. (2015). Theoretical and Methodological Aspects of Organization of Learning Process of Students of Higher School in Context of Theory of Constructivism [Teoretyko-metodychni aspekty orhanizatsiji protsesu navchannia studentiv vyshchoji shkoly $\mathrm{v}$ konteksti teoriji konstruktyvizmu]. Ukrainian Peda-gogical Journal, 4, 129-136 [in Ukrainian].

Savchenko, O. V. (2016). Reflexive competence: Methods and Procedures of Diagnostics [Refleksyvna kompetentnist: Metody i protsedury otsinky], Kherson: PP Vyshemyrskyi V.S. [in Ukrainian].

Schunk, D. H., \& Greene, J. A. (2018). Historical, contemporary, and future perspectives on self-regulated learning and performance, in D. H. Schunk \& J. A. Greene (Eds.), Educational psychology handbook series. Handbook of self-regulation of learning and performance (p. 115). Routledge/Taylor \& Francis Group.

Teslenko, M. M. \& Yudina, N. O. (2018). Psychological Peculiarities of Personality of Self-Regulation of Learning and Professional Activity of Students [Psykholohichni osoblyvosti samore-huliatsiji navchalno-profesijnoji dijalnosti studentiv]. Psycholo-gy and Personality, 1(13), 118-127 [in Ukrainian].

Zimmerman, B. (2011), Motivational sources and outcomes of selfregulated learning and performance, in B. Zimmerman and D. Schunk, (eds), Handbook of Self-Regulation of Learning and Performance, Abingdon: Routledge, 49-64.

Zimmerman, B. J. \& Kitsantas, A. (2006), A writer's discipline: the development of selfregulatory skill, in S. Hidi and P. Boscolo, (eds), Writing and Motivation, Amsterdam: Kluwer, 51-69. 